RESPUESTA

\title{
RESPUESTA AL DISCURSO DE INGRESO DE DON LUIS ASTEY A LA ACADEMIA MEXICANA DE LA LENGUA
}

\author{
Mtro. Manuel Alcalá*
}

\section{I}

Honró durante treinta y cinco años la silla número XXXVI Monseñor Octaviano Valdés. Humanista y gran conocedor de la literatura latina, cultivó también la poesía y la novela. De ello se han percatado ustedes por la memoria que de él ha traído para nosotros don Luis Astey. Su primera formación fue la del jurista. Obtuvo, en efecto, su licenciatura en Derecho y Ciencias Sociales en la Universidad Autónoma de Guadalajara, con título de la Universidad Nacional Autónoma de México. Su formación de jurista la corona con su vocación de humanista. Pero no exclusivamente en el campo de la literatura clásica latina, como su predecesor. Su terreno es otro y muy amplio.

Con una beca de la Alianza Francesa de México hizo estudios sobre literaturas antiguas del Cercano Oriente y sobre el drama latino medieval. Ello fue en la Facultad de Letras de la Universidad de París - Sorbona-y en la École Pratique des Hautes Études.

Su interés por el antiguo mundo del Cercano Oriente lo llevó a Madrid con una beca del Instituto de Cultura Hispánica. En la Villa del Oso y el Madroño hizo una investigación dirigida sobre antigua literatura mesopotámica. Ello fue en el Instituto Benito Arias Montano del Consejo Superior de Investigaciones Científicas.

En la Harvard Graduate School, con beca de la Fundación Rockefeller, hizo una investigación dirigida sobre literatura clásica griega.

* Miembro de la Academia Mexicana correspondiente de la Española. 


\section{MANUEL ALCALÁ}

Esa amplia y sólida preparación da sus frutos en la docencia, en la investigación y en diversas publicaciones. También las bibliotecas le deben mucho.

\section{II}

A sus veinticuatro años empieza su consagración a la docencia como profesor de tiempo completo en el Departamento de Humanidades del Instituto Tecnológico y de Estudios Superiores de Monterrey de septiembre de 1945 a julio de 1973. En esos mismos años fue profesor de Literatura Griega Clásica en la Facultad de Filosofía y Letras de la Universidad de Nuevo León. Pero en ella empezó su enseñanza en septiembre de 1951.

Desde mediados de 1973 lo tenemos en la ciudad de México dedicado siempre a la docencia en tres instituciones: la Facultad de Filosofía y Letras de la Universidad Nacional Autónoma de México, el Departamento de Estudios Generales del Instituto Tecnológico Autónomo de México y El Colegio de México.

En la primera fue profesor de asignatura (Literatura medieval) de septiembre de 1973 a julio de 1988, en la Licenciatura de Letras Hispánicas. Y desde septiembre de 1981 lo es en la División de Estudios de Posgrado. En el segundo se desempeña como profesor de tiempo completo y ha dado cursos de Historia de las Ideas. En el Centro de Estudios Lingǘ́sticos y Literarios de El Colegio de México profesa diversos cursos, principalmente de Literatura Medieval.

\section{III}

Por lo que atañe a la investigación, lo vemos en El Colegio de México desde septiembre de 1977 como Investigador de proyecto en el Centro de Estudios Lingüísticos y Literarios. Desde julio de 1988 en el mencionado Instituto Tecnológico Autónomo de México tiene derecho a dedicar a la investigación el sesenta por ciento del tiempo. Desde esa misma fecha hasta junio de 1991 estuvo en el Sistema Nacional de Investigadores, en el nivel II. Pasó al nivel III en julio de 1991 y sigue en él. Los temas de investigación son en Literatura y en Filología. 


\section{RESPUESTA}

Por lo que a bibliotecas de refiere, fue Director de la Biblioteca del Instituto Tecnológico y de Estudios Superiores de Monterrey de enero de 1961 a agosto de 1973.

También está empeñado en otras actividades.

Desde 1984 es Coordinador de la "Biblioteca Novohispana" en el Centro de Estudios Lingüísticos y Literarios de El Colegio de México. Es Miembro del Consejo de Redacción de la Nueva Revista de Filología de dicho Colegio, y también forma parte del Consejo Editorial de la Revista Estudios, publicada por el Departamento de Estudios Generales del Instituto Tecnológico Autónomo de México.

\section{IV}

Por lo que a sus publicaciones concierne, ellas son o bien originales, o bien traducciones directamente de textos mesopotámicos, griegos o latinos, o ya ediciones de temas medievales, todas ellas acompañadas de notas e introducciones.

De sus publicaciones originales, señalo Procedimientos de edición para la "Biblioteca Novohispana" que publicó El Colegio de México en 1985.

Por su interés en los temas mesopotámicos y del Cercano Oriente, señalo las cuatro siguientes: El poema de la creación "Enuma elish" que se publicó en Monterrey en 1961 al cobijo de Arte A.C. y de la Asociación de Estudiantes de Arquitectura del Instituto de Estudios Superiores de Monterrey. Ese mismo año y en Monterrey también la revista Humanitas publica, en sus páginas 299 a 323, "El mito acadio de Zu y dos documentos afines". Siempre en Humanitas de Monterrey —páginas 237 a 256-, "Algunos textos sumeroacadios de la creación". Cultiva afanoso el tema de su primera publicación, Enuma elish cuya traducción publica en 1989 la Universidad Autónoma Metropolitana.

Menciono sus dos publicaciones en el terreno del mundo griego. La primera apareció en Monterrey y en 1967, en las páginas 45-119 del número I de Cuadernos de humanidades. Se intitula "La teogonía hesiódica". La segunda, todavía inconclusa, "Sofistas, dioses y literatura", se ha venido publicando en Estudios de la ciudad de México, número 2, 1985, páginas 77-83; número 3, páginas 91-104 y número 4 de 1986, páginas 49-84. 


\section{MANUEL ALCALÁ}

Pero son más numerosas sus publicaciones —once hasta ahorasobre la literatura latina medieval. Entre ellas descuellan las dedicadas a la monja Rosvitha de Gandersheim. La Sor Juana Inés de la Cruz del siglo X, me atrevo a decir. En el número I de 1966 de los Cuadernos de Investigación Humanística de Monterrey, y en las páginas 175-202, publica "Rosvitha de Gandersheim", Dulcidio (Dulcitius). En la colección Poesía en el Mundo de Monterrey y en 1969 sale de la imprenta Rosvitha de Gandersheim, "Calímaco". Finalmente en 1990 publica en traducción suya y con notas Los seis dramas de la misma monja. Fue una coedición del Fondo de Cultura Económica y el Instituto Tecnológico Autónomo de México.

Me quedan todavía por mencionar ocho publicaciones sobre temas medievales:

"Sponsus": un drama medieval latino-romántico. Colección Poesía en el mundo número 46, 1967, Monterrey. Hay segunda edición de 1969.

"El Danielis ludus de la Catedral de Beauvais", en Humanitas de Monterrey, número 10, 1959, p. 307-325.

El "Ludus de Nativitate" de Benediktbeuern. Colección Poesía en el Mundo, número 80, 1970, Monterrey.

Dramas latinos medievales del ciclo de Navidad, 1970, Monterrey: Instituto Tecnológico y de Estudios Superiores de Monterrey. Es el número 4 de la Serie Letras de las publicaciones de dicho Instituto.

"Peregrinus": Tres versiones, Colección Poesía en el Mundo, número 91, 1971, Monterrey.

Una edición del "Pergamino Vindel", Colección Poesía en el Mundo, número 130, 1978, Monterrey.

El Ordo Virtutum de Hildegard von Bingen", en las páginas 17-52 del tomo II: Literatura del libro Reflexiones Lingüísticas y Literarias editado por R. Olea Franco y J. Valender. 1992, El Colegio de México, Estudios de Lingüística y Literatura, XXI.

Dramas litúrgicos del Occidente medieval, 1992, en Coedición de El Colegio de México, CONACYT y el Instituto Tecnológico Autónomo de México. 
RESPUESTA

Y ahora acaba de ilustrarnos y deleitarnos con su discurso. El glosarlo sería impertinencia mía, pues quitaría el buen sabor que nos ha quedado. No dejo de admirar el perfecto equilibrio de los tres tópicos que lo constituyen.

En el segundo nos ha dado una excelente visión del nacimiento y amplia difusión de la leyenda de Teófilo en el mundo occidental. A propósito del papel de la Mater gloriosa en el Fausto de Goethe ha acuñado, como buen lingüista, la voz actancia. Lo hizo partiendo del francés actante, término del crítico teórico estructuralista francés Greimas. Divide éste al personaje, sea de teatro o de novela en acteur y en actante. El primero es el personaje caracterizado mediante la palabra; el segundo, mediante la acción. Claro que hay personajes que son a la vez acteurs y actantes.

En el tercer tópico nos ha ofrecido su excelente traducción de la versión latina que dan los Acta Sanctorum. Son ellos una recopilación de vidas de santos en la que trabajan desde el siglo XVII los beneméritos Bolandistas. Pudo manejar — nos ha dicho-esa rara edición de 1658 en el rico Fondo de Origen de la Biblioteca Nacional de México.

\section{VI}

Su amplio y sólido humanismo, su buen conocimiento de nuestra lengua, amén de otros méritos, le abrieron las puertas de nuestra Casa como académico electo. Esta noche, por el docto discurso que acabamos de escucharle, es ya académico de número. Y en ese discurso, parte medular ha sido su versión de la leyenda de Teófilo. Versión en la que en excelente español ha conservado el candoroso encanto del latín de la traducción de los Bolandistas.

Por todo ello, me es grato dar a don Luis Astey la bienvenida a nuestra Academia, con el beneplácito y el aplauso de sus colegas. 